\title{
One-stop Centre for Intravenous Iron Administration to Iron-deficiency Anaemic Patients Planned for Major Surgery
}

\author{
Qing Yuan Goh ${ }^{1}$, Anne Sheng Chuu Kiew², Huae Min Tham², Mischelle Calvo Tui ${ }^{3}$, Avinash Gobindram ${ }^{2}$ \\ ${ }^{1}$ Singhealth Anaesthesiology Residency Program, Singapore. ${ }^{2}$ Department of Anaesthesia and Surgical Intensive Care, Changi General Hospital (CGH), Singapore.
} ${ }^{3}$ Pre-Anaesthesia Assessment Clinic, CGH, Singapore

\section{Background}

- Large percentage of preoperative patients suffer from iron-deficiency anaemia ${ }^{1}$.

- Correction of iron-deficiency anaemia has been shown to decrease the need for blood transfusions, morbidity and mortality ${ }^{2}$.

- Iron supplementation preoperatively is not common in our region Goals

- Develop a pathway to manage patients with iron-deficiency anaemia who are planned for major surgery

- Identify this group of patients among all preoperative patients being routinely screened by anaesthetists at Pre-Anaesthesia Assessment Clinic (PAAC)

- PAAC will then serve as a one-stop centre to minimise frequency of blood sampling, clinic visits

- Administer IV iron or prescribe oral iron at the same siting

Methods

- Multi-disciplinary consultations with the Department of Anaesthesia and Surgical Intensive Care, staff of PAAC, haematologists, surgeons, pharmacists and laboratory technicians in CGH

- Formulate pathway for administration of IV iron

$\underline{\text { Results }}$

- Over 6 months, 14 patients were treated with IV iron and 4 were treated with oral iron tablets

- In the group treated with IV iron:

$>$ Mean $\mathrm{Hb}$ level at $1^{\text {st }}$ PAAC visit: $9.6 \mathrm{~g} / \mathrm{dL}$ ( 8.4 to $10.8 \mathrm{~g} / \mathrm{dL}$ )

$>$ No patients developed side effects during administration of IV iron

$>$ Mean $\mathrm{Hb}$ level after IV iron: $10.1 \mathrm{~g} / \mathrm{dL}(8.4$ to $11.9 \mathrm{~g} / \mathrm{dL})$

$>$ Change in $\mathrm{Hb}$ level: $+0.7 \mathrm{~g} / \mathrm{dL}(-0.9$ to $+2.4 \mathrm{~g} / \mathrm{dL})$

$>6$ patients received blood transfusions perioperatively

$>1$ patient developed severe hypophosphatemia (0.35-0.5 $\mathrm{mmol} / \mathrm{L}$ ) secondary to phosphaturia due to IV iron

\section{Conclusion}

- Detection \& treatment of iron-deficiency anaemia could be safely and effectively instituted at a one-stop centre

- IV iron administration was able to raise the Hb levels of our patients prior to surgery

- Phosphate levels are now checked in patients who had received IV iron

- Further studies will be required to determine the side effects and extent of decrease in blood transfusion requirement, morbidity, mortality with iron supplementation in this high-risk group of patients

\section{$\underline{\text { References }}$}

1. L.T. Goodnough et al. Detection, evaluation, and management of preoperative anaemia in the elective orthopaedic surgical patient: NATA guidelines. Br J Anaesth. 2011 Jan;106(1):13-22

2. Muñoz M et al. 'Fit to fly': overcoming barriers to preoperative haemoglobin optimization in surgical patients. Br J Anaesth. 2015 Jul;115(1):15-24

\section{List 1: High-risk surgery}

General rule:

- Any procedure with anticipated blood loss of $>1000 \mathrm{ml}$

Specific procedures:

- Vascular: any aortic procedures

- General Surgery: any colorectal, hepatic, gastric, oesophageal surgery

- Urology: nephrectomy or prostatectomy

- Orthopaedic: any major joint replacement (knee, hip, shoulder),spine surgery

- OMS/ENT/plastic: major head and neck surgery and/or any flap surgery

List 2: Contraindications for IV Ferric Carboxymaltose

- History of asthma

- Allergic eczema or other atopic allergy

- Iron overload or disturbances in utilisation of iron (eg: haemochromatosis)

- Active infection (sepsis, acute and chronic infection)

- Decompensated liver disease (cirrhosis and hepatitis with abnormal liver function)

- Rheumatoid arthritis with evidence of active inflammation

\section{in}

Return to PAAC for IV Ferric Carboxymaltose infusion under close monitoring

Arrival in PAAC

- Request for Iron Panel + routine investigations (FBC, renal panel etc.) if not done in last 6 months

- If $\mathrm{Hb}<10 \mathrm{~g} / \mathrm{dL}$, consider speaking to surgeon about postponing surgery, to investigate and treat anaemia in non-urgent cases

Iron deficiency: Ferritin $<200 \mathrm{ug} / \mathrm{L}, \quad$ No $\rightarrow$ Manage anaemia according to Iron saturation $<20 \%$ PAAC's guidelines

Give patient prescription and sample voucher for Ferric Carboxymaltose, in order to collect drug from Pharmacy
- IV Ferric Carboxymaltose

- Exclude contraindications to IV

Ferric Carboxymaltose (list 2)

- Determine required dosage (table 1)

- Determine dosing regimen (table 2)

Only 1 session required

$1^{\text {st }}$ prescription

Generate 2 or 3 prescriptions

Patient to return to PAAC 1 week after $1^{\text {st }}$ session to obtain remaining prescription \& sample voucher to collect drug from Pharmacy

Check Full Blood Count preoperatively (pre or post induction) to monitor $\mathrm{Hb}$ response to IV iron therapy

Table 1: Required dosing

\begin{tabular}{|l|l|l|}
\hline $\begin{array}{l}\text { Hb } \\
(\mathrm{g} / \mathrm{dL})\end{array}$ & $\begin{array}{l}\text { Weight } \\
(35-70 \mathrm{~kg})\end{array}$ & $\begin{array}{l}\text { Weight } \\
(>70 \mathrm{~kg})\end{array}$ \\
\hline$<10$ & $1500 \mathrm{mg}$ & $2000 \mathrm{mg}$ \\
\hline$\geq 10$ & $1000 \mathrm{mg}$ & $1500 \mathrm{mg}$ \\
\hline
\end{tabular}

Table 2: Dosing regimen

Max dose of IV iron: $20 \mathrm{mg} / \mathrm{kg}$, up to max of $1000 \mathrm{mg}$ per week should be 1 week apart
Patient A: 40kg, Hb 9g/dL: will require $1500 \mathrm{mg}$ of IV iron Max dose per week: $800 \mathrm{mg}$ Prescribe IV iron $800 \mathrm{mg}$ for $1^{\text {st }}$ session and another $700 \mathrm{mg}$ for $2^{\text {nd }}$ session 1 week later

Patient B: 80kg, Hb 11 g/dL; will require $1500 \mathrm{mg}$ of IV iron

Prescribe IV iron $1000 \mathrm{mg}$ for $1^{\text {st }}$ session and another $500 \mathrm{mg}$ for $2^{\text {nd }}$ session

Patient $C$ : 60kg, Hb 10.5 g/dL; will require $1000 \mathrm{mg}$ of IV iron Prescribe IV iron $1000 \mathrm{mg}$ for 1 session 